\title{
OPTIMIZATION OF AN INTRA-SUPPLY CHAIN SYSTEM WITH UNRELIABLE PRODUCTION FACILITY
}

\author{
Singa Wang Chiu' ${ }^{1}$ Hsin-Mei Chen ${ }^{2}$ Hong-Dar Lin ${ }^{2}$ Yuan-Shyi Peter Chiu ${ }^{2 *}$ \\ ${ }^{1}$ Department of Business Administration, Chaoyang University of Technology, Taiwan \\ ${ }^{2}$ Department of Industrial Engineering \& Management, Chaoyang University of Technology, Taiwan
}

\begin{abstract}
Optimization of a manufacturer-retailer integrated type of intra-supply chain system considering unreliable production facility is explored in this study. It is assumed that a producer of consumer goods has its own sales offices, and during the fabrication process, both equipment breakdown and production of nonconforming goods seem inevitable. To explicitly address such a real intra-supply chain problem, we incorporate end products transportation cost and sales office's stock holding cost into a prior study (Chiu [01]) with the objective of deriving the optimal fabrication runtime. Solution to the problem is obtained through the use of mathematical modeling, optimization techniques, and a proposed recursive algorithm. Applicability of research result and sensitivity analyses are demonstrated thru numerical example.
\end{abstract}

Key words: Optimizer, Manufacturer-retailer integrated system, Optimal fabrication runtime, Unreliable facility, Intra-supply chain system, Rework, Multiple shipments

\section{INTRODUCTION}

This study investigates the optimal fabrication runtime for a manufacturer-retailer integrated intra-supply chain system with stochastic machine breakdown and the reworking of defective items. Economic production quantity (EPQ) based model has been constantly utilized in manufacturing sector to help derive the most economical batch size (or runtime) that minimizes total fabrication and stock holding costs [02-04]. Assumption of EPQ model [02] is simplified, it includes (i) a continuous inventory issuing policy of end products, (ii) all products made are of perfect quality, and (iii) the manufacturing equipment is always in perfect operating condition during a production run. However, in the existing supply chain environments, the assumption of a continuous issuing policy of end products is somewhat impractical because of the enormous transportation costs incurred. Consequently, the periodic multi-shipment policy is often implemented. Goyal [05] proposed a vendor-buyer integrated supply-chain system. Numerical illustrations were used to demonstrate applicability of his proposed solution process to the problem. The fill-rate of a one-warehouse multi-retailer system with was investigated via an existing approximation method by Schwarz et al. [06]. Several properties of the fill-rate policy were presented to help managerial decision makings. Banerjee and Banerjee [07] used an electronic data interchange (EDI) approach to explore a one-vendor multi-buyer inventory system under the policy of rotation fabrication cycle length. Computations of values of diverse system parameters were executed by a proposed algorithm to demonstrate how their research results are beneficial to all parties in the system. Tyan and Wee [8] used real data from Taiwanese grocery industry to investigate characteristics of the supplier-retailer partnership. The result indicated that the vendor managed inventory (VMI) case can help improve service level and cut down costs for both parties in the system. Additional studies [09-17] explored diverse aspects of supply-chain management.

Contrasting to conventional EPQ model which implicitly assumes a perfect manufacturing condition, in real-life fabrication systems owing to process deterioration and diverse unpredictable reasons, manufacturing equipment failure and output of nonconforming products are inevitable. Henig and Gerchak [18] analyzed structure of a general periodic review production-inventory system considering variable yield. Groenevelt et al. [19] explored the effects of stochastic machine breakdown under two distinct inventory control policies. One is the no-resumption (NR) policy and the other is the abort resume (AR) policy; the former policy assumed that if an equipment failure happens, fabrication of the interrupted batch will not be resumed, while the latter (i.e., AR policy) assumed that if the level of on-hand inventories falls below a preset threshold point at the time of machine breakdowns, then fabrication of the interrupted batch is resumed immediately once the production equipment is repaired. Based on these policies, the exact optimal and the approximate batch size formulae were derived, respectively. Boone et al. [20] utilized the mathematical modeling technique to investigate impact of imperfect processes on fabrication runtime for a manufacturing system with defectives and equipment failure. Lin and Gong [21] explored an EPQ model subject to an exponential decay and under a no resumption stock controlling policy. As a result, they derived a near optimal runtime under the conditions of deterministic demand, no stock-out permitted, and continuous review policy. Sana and Chaudhuri [22] investigated economic manufacturing quantity (EMQ) system wherein the fabrication processes are not perfect. Both the NR 
and AR policies were taken into account on breakdown incident. Accordingly, they determined the optimal manufacturing lot-size, fabrication rate, and safety stock. Chiu [01] solved a production runtime problem featuring rework of nonconforming items and Poisson breakdown under an AR inventory control policy. They first derived the expected cost function for their proposed system and then presented theorems on convexity as well as bounds of production runtime. With the help of a recursive algorithm they were able to locate the optimal fabrication runtime. Other studies [23-39] also addressed diverse aspects of fabrication systems featuring defective products, rework, and stochastic failure of equipment.

This paper extends a prior study (Chiu [01]) by incorporating the shipping cost of end products and stock holding cost of sales offices into Chiu's model and resolves the optimal replenishment cycle time for such an intra-supple chain system. Since this particular area has not been a focus of attention, the present work aims to bridge the research gap.

\section{MATERIALS AND METHODS}

\section{Problem statement}

Manufacturers of consumer goods operating in present-day supply chain environments often have their own sales offices to put their end products on the market. To specifically address such an intra-supply chains situation, we extend Chiu's model [01] by incorporating the shipping cost of end products and stock holding cost of sales offices into Chiu's model, and resolves the optimal replenishment cycle time for such an intra-supple chain system (see Figure 1).

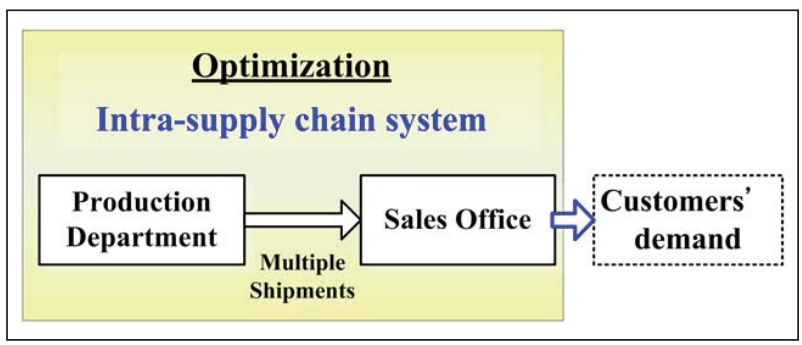

Figure 1: Extension of Chiu's model [01] to an intra-supply chain system

Description of the proposed model is as follows. Considering the annual demand rate for a manufactured item is $\lambda$ and this product can be fabricated at an annual rate of $P 1$. In the fabrication process of this item, $x$ proportion of nonconforming item is produced randomly. Hence, production rate of nonconforming products $d 1=P 1 x$. Shortage is not allowed in this study, so $(P 1-d 1-\lambda)>0$ is assumed. To guarantee conformance of quality, all manufactured products are inspected and this relevant cost is considered a part of unit manufacturing cost $C$. With the intention of lowering cost and improving quality, all nonconforming products can be reworked and repaired, at a rate of $P 2$ when regular fabrication process ends. In the finishing point of rework process, end products are distributed to the sales office, under a discontinuous multi-shipment policy, whereas $n$ fixed amount installments of the completed batch are delivered at a fixed interval of time during product delivery time of each replenishment cycle.

It is further assumed that in fabrication process the production equipment is subject to a stochastic failure that obeys the Poisson distribution. An AR policy is adopted once a machine failure happens. Under the AR policy, production equipment will be repaired right away, and the interrupted batch is resumed immediately once the equipment is restored. In this study, we assume the repair time $g$ for breakdown is constant and in the case that the repair time exceeds $g$, a spare equipment will be used immediately to avoid further delay of the remaining fabrication process. To ease readers' comparison efforts, the same notation (see Appendix A) is adopted as that in Chiu [01]. Let $\beta$ denote the mean of Poisson machine failure rate and $\mathrm{t}$ be the fabrication time to a machine failure occurrence. Two separate cases as shown in the following subsections should to be explored, respectively.

\section{Mathematical modeling \& analysis}

\section{Case 1: A machine failure happens in fabrication uptime}

Case one describes that the time to a machine failure is shorter than fabrication uptime (i.e., $t<t 1$ ). Because the $A / R$ is used, the machine goes under repair at once, and fabrication of the interrupted batch resumed instantaneously when machine is restored. Figure 2 illustrates the on-hand inventory level of perfect quality products during a replenishment cycle at the production unit.

By observing Figure 2, it can be seen that when an equipment breakdown happens, the on-hand stock level stays at $H 2^{\prime}$ for a period of time $t_{r}$ (i.e., the repair time) till machine is restored. Then, the level of inventory continues to pile up during fabrication of the remaining batch to a level of $\mathrm{H}^{\prime}$ ' in the end of regular fabrication process. It follows that the reworking of nonconforming products during $t 2$ ' brings the level of inventory to $H^{\prime}$. So, the replenishment cycle length $T^{\prime}$ is as follows:

$$
T^{\prime}=t_{1}+t_{r}+t_{2}^{\prime}+t_{3}^{\prime}
$$

Upon completion of rework, the total nonconforming products, cost for rework, and cost for holding reworked products are given as follows:

$$
\begin{aligned}
& d_{1} t_{1}=x P_{1} t_{1} \\
& C_{R}\left(t_{1} P_{1} x\right) \\
& h_{1} \frac{d_{1} t_{1}}{2} t_{2}^{\prime}
\end{aligned}
$$




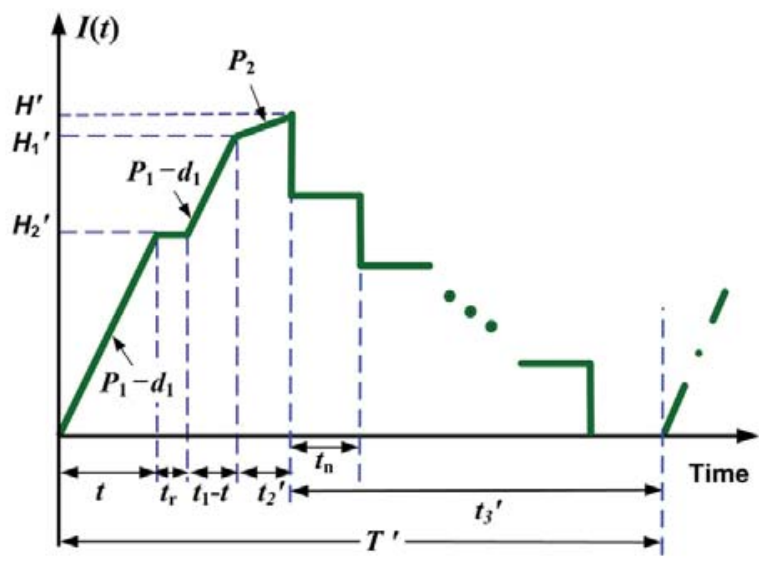

Figure 2: The on-hand stock level during a replenishment cycle [01]

Equation (5) exhibits total fabrication-inventory-transportation cost per replenishment cycle in the production unit, it consists of (i) variable fabrication cost, (ii) setup cost, (iii) repair cost for failure equipment, (iv) cost for rework, (v) cost for holding reworked products, (vi) fixed and variable shipping costs, (vii) holding cost for safety stocks; and (viii) inventory holding costs for perfect quality and nonconforming products in the entire replenishment cycle.

$$
\begin{aligned}
& C\left(P_{1} t_{1}\right)+K+M+C_{R}\left(x P_{1} t_{1}\right)+h_{1} \frac{d_{1} t_{1}}{2} t_{2}^{\prime} \\
& +n K_{1}+C_{T}\left(P_{1} t_{1}\right)+h_{3}\left(\lambda t_{r}\right) T^{\prime} \\
& +h\left[\frac{H_{1}^{\prime}+d_{1} t_{1}}{2} t_{1}+\left(H_{2}^{\prime}+d_{1} t\right) t_{r}+\right. \\
& \left.+\frac{H_{1}^{\prime}+H^{\prime}}{2}\left(t_{2}^{\prime}\right)+\frac{n-1}{2 n} H^{\prime} t_{3}^{\prime}\right]
\end{aligned}
$$

Figure 3 shows the status of sales office's on-hand stock level in replenishment cycle, where the product demand between two consecutive shipments is $\lambda t_{n}$, and leftover products in each fixed time interval tn (after $\lambda t_{n}$ being satisfied) is as follows:

$$
I=D-\lambda t_{n}
$$

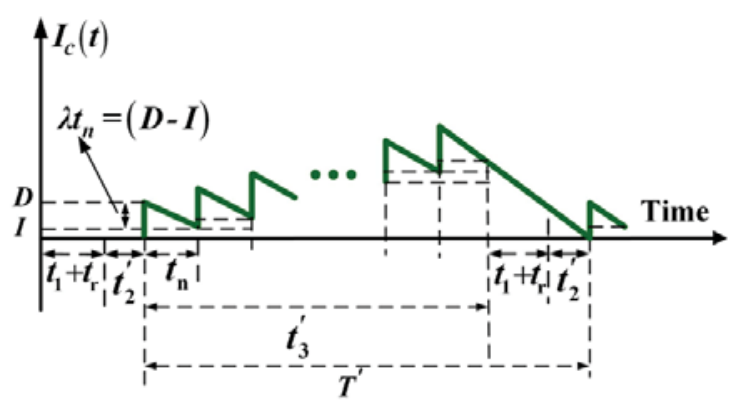

Figure 3: The sales office's on-hand inventory level during a replenishment cycle
Equation (7) shows total stock holding cost in the sales office.

$$
h_{2}\left[\frac{n(n+1)}{2} I t_{n}+n \frac{(D-I)}{2} t_{n}+\frac{n I}{2}\left(t_{1}+t_{r}+t_{2}^{\prime}\right)\right]
$$

Incorporating the aforementioned sales office's stock holding cost into Chiu's model [01], we obtain the total system cost $T C_{1}\left(t_{1}\right)$ for our proposed model as follows:

$$
\begin{aligned}
& T C_{1}\left(t_{1}\right)=C\left(P_{1} t_{1}\right)+K+M+C_{R}\left(x P_{1} t_{1}\right)+ \\
& +h_{1} \frac{d_{1} t_{1}}{2} t_{2}^{\prime}+n K_{1}+C_{T}\left(P_{1} t_{1}\right)+h_{3}\left(\lambda t_{r}\right) T^{\prime} \\
& +h\left[\frac{H_{1}^{\prime}+d_{1} t_{1}}{2} t_{1}+\frac{H_{1}^{\prime}+H^{\prime}}{2}\left(t_{2}^{\prime}\right)+\left(H_{2}^{\prime}+d_{1} t\right) t_{r}+\frac{n-1}{2 n} H^{\prime} t_{3}^{\prime}\right] \\
& +h_{2}\left[\frac{n(n+1)}{2} I t_{n}+n \frac{(D-I)}{2} t_{n}+\frac{n I}{2}\left(t_{1}+t_{r}+t_{2}^{\prime}\right)\right]
\end{aligned}
$$

For the reason that $x$ is a random variable, we use expected value to cope with its randomness, and by substituting relevant system variables in Equation (8) and with additional derivations, $E\left[T C_{1}\left(t_{1}\right)\right]$ is gained as shown in Equation (9).

$$
\begin{aligned}
& E\left[T C_{1}\left(t_{1}\right)\right]=K+M+n K_{1}+h t P_{1} g \\
& +\left[C P_{1}+C_{R} P_{1} E[x]+C_{T} P_{1}+h_{3} P_{1} g-\frac{P_{1} g\left(h-h_{2}\right)}{2}\left(1-\frac{1}{n}\right)\right] \cdot t_{1} \\
& +\left[\begin{array}{l}
\frac{h P_{1}^{2}}{2 \lambda}+\frac{h P_{1}^{2} E[x]}{P_{2}}(1-E[x])+\frac{h_{1} P_{1}^{2} E[x]^{2}}{2 P_{2}}+\frac{h_{2} P_{1}}{2} \\
+\frac{h_{2} P_{1}^{2} E[x]}{2 P_{2}}+\frac{\left(h-h_{2}\right) P_{1}}{2 n}\left[\frac{P_{1} E[x]}{P_{2}}+1-\frac{P_{1}}{\lambda}\right]
\end{array}\right] t_{1}^{2}
\end{aligned}
$$

\section{Case 2: No machine failure happens in fabrication uptime}

Case two expresses that the time to a machine failure is longer than fabrication uptime (i.e., $t>t_{1}$ ). In other words, machine failure does not take place in fabrication process (Figure 4).

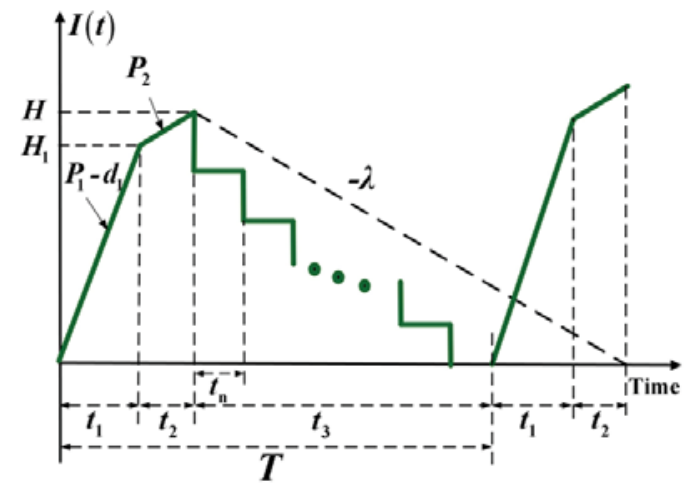

Figure 4: The on-hand stock level during a replenishment cycle when machine failure does not take place 
The fabrication cycle length $T$ in Case 2 is as follows:

$$
T=t_{1}+t_{2}+t_{3}
$$

Equation (11) shows total fabrication-inventory-transportation cost per replenishment cycle in the production unit, it comprises (i) variable fabrication cost, (ii) setup cost, (iii) repair cost for failure equipment, (iv) cost for rework, (v) cost for holding reworked products, (vi) fixed and variable shipping costs, (vii) holding cost for safety stocks; and (viii) inventory holding costs for perfect quality and nonconforming products in the entire replenishment cycle.

$$
\begin{aligned}
& C\left(P_{1} t_{1}\right)+K+C_{R}\left(x P_{1} t_{1}\right)+h_{1} \frac{d_{1} t_{1}}{2} t_{2}+n K_{1}+C_{T}\left(P_{1} t_{1}\right) \\
& +h_{3}\left(\lambda t_{r}\right) T+h\left[\frac{H_{1}+d_{1} t_{1}}{2} t_{1}+\frac{H_{1}+H}{2}\left(t_{2}\right)+\frac{n-1}{2 n} H t_{3}\right]
\end{aligned}
$$

Equation (12) gives the total stock holding cost in the sales office.

$$
h_{2}\left[\frac{n(n+1)}{2} I t_{n}+n \frac{(D-I)}{2} t_{n}+\frac{n I}{2}\left(t_{1}+t_{2}\right)\right]
$$

Incorporating the aforementioned sales office's stock holding cost into Equation (11), we obtain the total system cost $T C_{2}\left(t_{1}\right)$ for our proposed model as follows:

$$
\begin{aligned}
& T C_{2}\left(t_{1}\right)=C\left(P_{1} t_{1}\right)+K+C_{R}\left(x P_{1} t_{1}\right)+ \\
& +h_{1} \frac{d_{1} t_{1}}{2} t_{2}+n K_{1}+C_{T}\left(P_{1} t_{1}\right) \\
& +h_{3}\left(\lambda t_{r}\right) T+h\left[\frac{H_{1}+d_{1} t_{1}}{2} t_{1}+\frac{H_{1}+H}{2}\left(t_{2}\right)+\frac{n-1}{2 n} H t_{3}\right] \\
& +h_{2}\left[\frac{n(n+1)}{2} I t_{n}+n \frac{(D-I)}{2} t_{n}+\frac{n I}{2}\left(t_{1}+t_{2}\right)\right]
\end{aligned}
$$

Applying expected value of $x$ to cope with its randomness, and substituting relevant system variables in Equation (13) and with extra derivations, $E\left[T C_{2}\left(t_{1}\right)\right]$ can be obtained as shown in Equation (14).

$$
\begin{aligned}
& E\left[T C_{2}\left(t_{1}\right)\right]=\left[C P_{1}+C_{R} P_{1} E[x]+C_{T} P_{1}+h_{3} P_{1} g\right] t_{1}+K+n K_{1} \\
& +\left[\begin{array}{l}
\frac{h P_{1}^{2}}{2 \lambda}+\frac{h P_{1}^{2} E[x]}{P_{2}}(1-E[x])+\frac{h_{1} P_{1}^{2} E[x]^{2}}{2 P_{2}}+\frac{h_{2} P_{1}}{2} \\
+\frac{h_{2} P_{1}^{2} E[x]}{2 P_{2}}+\frac{\left(h-h_{2}\right) P_{1}}{2 n}\left[\frac{P_{1} E[x]}{P_{2}}+1-\frac{P_{1}}{\lambda}\right]
\end{array}\right] t_{1}^{2}
\end{aligned}
$$

\section{Integration of cases 1 and 2}

Since fabrication process is subject to a Poisson distribution equipment failure rate. So, time to an equipment failure follows the exponential distribution with density function $f(t)=\beta e^{-\beta t}$ and the cumulative density function $\mathrm{F}(\mathrm{t})=$ $1-e^{-\beta t}$. To calculate $E\left[T C U\left(t_{1}\right)\right]$, we need to integrate cost functions in both case one and two, and consider the expected cycle length to cope with its variation as follows:

$$
E\left[T C U\left(t_{1}\right)\right]=\frac{\left\{\int_{0}^{t_{1}} E\left[T C_{1}\left(t_{1}\right)\right] f(t) d t+\int_{t_{1}}^{\infty} E\left[T C_{2}\left(t_{1}\right)\right] f(t) d t\right\}}{\mathrm{E}[T]}
$$

where

$$
\mathrm{E}[\boldsymbol{T}]=\int_{0}^{t_{1}} E\left[T^{\prime}\right] f(t) d t+\int_{t_{1}}^{\infty} E[T] f(t) d t
$$

Substitute Equations (9), (14), and (16) into Equation (15), and with extra derivations we obtain $E\left[T C U_{2}\left(t_{1}\right)\right]$ as shown in Equation (17).

$$
\begin{aligned}
& E\left[\operatorname{TCU}\left(t_{1}\right)\right]= \\
& \int\left(C+C_{R} E[x]+C_{T}+h_{3} g\right)+\frac{\left(K+n K_{1}\right)}{t_{1} P_{1}}-h g\left(e^{-\beta_{1}}\right) \\
& =\lambda\left\{+\frac{1}{2}\left[\begin{array}{l}
\frac{h P_{1}}{\lambda}+\frac{h P_{1} E[x]}{P_{2}}(1-E[x])+\frac{h_{1} P_{1} E[x]^{2}}{P_{2}}+h_{2} \\
+\frac{\left(h-h_{2}\right)}{n}\left[\frac{P_{1} E[x]}{P_{2}}+1-\frac{P_{1}}{\lambda}\right]+\frac{h_{2} P_{1} E[x]}{P_{2}}
\end{array}\right] \cdot t_{1}\right. \\
& \left.+\left[\frac{M}{P_{1}}+\frac{h g}{\beta}\right]\left(\frac{1-e^{-\beta \hbar_{4}}}{t_{1}}\right)-\left(h-h_{2}\right)\left[\frac{g}{2}\left(1-\frac{1}{n}\right)\right]\left(1-e^{-\beta \xi_{4}}\right)\right]
\end{aligned}
$$

or

$$
=\lambda\left\{\begin{array}{c}
E\left[\operatorname{TCU}\left(t_{1}\right)\right]= \\
\pi_{1}+\frac{\left(K+n K_{1}\right)}{t_{1} P_{1}}+\pi_{2} t_{1}+\left[\frac{M}{P_{1}}+\frac{h g}{\beta}\right]\left(\frac{1-e^{-\beta \beta_{1}}}{t_{1}}\right) \\
-h g\left(e^{-\beta \ell_{4}}\right)-\left(h-h_{2}\right)\left[\frac{g}{2}\left(1-\frac{1}{n}\right)\right]\left(1-e^{-\beta t_{4}}\right)
\end{array}\right\}
$$

where

$$
\pi_{1}=\left[C+C_{R} E[x]+C_{T}+h_{3} g\right]
$$

and

$$
\begin{aligned}
& \pi_{2}=\frac{1}{2}\left[\frac{h P_{1}}{\lambda}+\frac{h P_{1} E[x]}{P_{2}}(1-E[x])+\frac{h_{1} P_{1} E[x]^{2}}{P_{2}}+h_{2}+\right. \\
& \left.+\frac{\left(h-h_{2}\right)}{n}\left[\frac{P_{1} E[x]}{P_{2}}+1-\frac{P_{1}}{\lambda}\right]+\frac{h_{2} P_{1} E[x]}{P_{2}}\right]
\end{aligned}
$$

\section{RESULTS AND DISCUSSION}

\section{Convexity and optimal fabrication runtime}

Once $E\left[T C U\left(t_{1}\right)\right]$ is obtained, we apply second-derivative of Equation (18) with respect to $t_{1}$ to test for convexity as follows:

$$
\begin{gathered}
\frac{d^{2} E\left[T C U\left(t_{1}\right)\right]}{d^{2} t_{1}^{2}}= \\
=\lambda\left\{\begin{array}{l}
\frac{2\left(K+n K_{1}\right)}{t_{1}^{3} P_{1}}-\left(h-h_{2}\right)\left[\frac{g}{2}\left(1-\frac{1}{n}\right)\right]\left(\beta^{2} e^{-\beta t_{1}}\right)-h g\left(\beta^{2} e^{-\beta t_{1}}\right) \\
+\left[\frac{M}{P_{1}}+\frac{h g}{\beta}\right]\left(\frac{2\left(1-e^{-\beta \beta_{1}}\right)}{t_{1}^{3}}-\frac{2 \beta e^{-\beta t_{1}}}{t_{1}^{2}}-\frac{\beta^{2} e^{-\beta t_{1}}}{t_{1}}\right)
\end{array}\right\}
\end{gathered}
$$


Because annual demand $\lambda>0$, to show that Equation (20) $>0$ is equivalent to demonstrate that Equation (21) $>0$.

$$
\left\{\begin{array}{l}
\frac{2\left(K+n K_{1}\right)}{t_{1}^{3} P_{1}}-\left[\left(h-h_{2}\right)\left[\frac{g}{2}\left(1-\frac{1}{n}\right)\right]-h g\right]\left(\beta^{2} e^{-\beta_{4}}\right) \\
+\left[\frac{M}{P_{1}}+\frac{h g}{\beta}\right]\left[\frac{2\left(1-e^{-\beta \beta_{4}}\right)}{t_{1}^{3}}-\frac{2 \beta e^{-\beta_{4}}}{t_{1}^{2}}-\frac{\beta^{2} e^{-\beta t_{4}}}{t_{1}}\right)
\end{array}\right\}>0
$$

That is

if $\left\{\begin{array}{l}2\left(K+n K_{1}\right) \beta-\left[\left(h-h_{2}\right)\left[\frac{g}{2}\left(1-\frac{1}{n}\right)\right]+h g\right]\left(\beta^{2} e^{-\beta_{1}}\right)\left(t_{1}^{3} P_{1} \beta\right) \\ +\left(M \beta+h g P_{1}\right)\left[2\left(1-e^{-\beta_{1}}\right)-\left(2 \beta e^{-\beta_{1}}\right) t_{1}-\left(\beta^{2} e^{-\beta_{1}}\right) t_{1}^{2}\right]\end{array}\right\}>0$

then $\frac{d^{2} E\left[T C U\left(t_{1}\right)\right]}{d t_{1}^{2}}>0$

Let

$$
\pi_{3}=\left[\left(h-h_{2}\right)\left[\frac{g}{2}\left(1-\frac{1}{n}\right)\right]+h g\right]
$$

and $\pi_{4}=M \beta+h g P_{1}$

Substitute Equations (23) and (24) in Equation (22), it becomes as follows:

if $\left\{\begin{array}{l}2\left(K+n K_{1}\right) \beta-\pi_{3}\left(\beta^{2} e^{-\beta t_{1}}\right)\left(t_{1}^{3} P_{1} \beta\right) \\ +\pi_{4}\left[2\left(1-e^{-\beta t_{1}}\right)-\left(2 \beta e^{-\beta t_{1}}\right) t_{1}-\left(\beta^{2} e^{-\beta t_{1}}\right) t_{1}^{2}\right]\end{array}\right\}>0$

then $\frac{d^{2} E\left[T C U\left(t_{1}\right)\right]}{d t_{1}^{2}}>0$

The left-hand side of Equation (25) can be rearranged as

$$
\text { if } \begin{aligned}
& \left\{2\left(K+n K_{1}\right) \beta+2\left(1-e^{-\beta t_{1}}\right) \pi_{4}-\right. \\
& \left.-\left[\pi_{3} \beta^{2} P_{1} t_{1}^{2}+\pi_{4}\left(2+\beta t_{1}\right)\right]\left(\beta e^{-\beta t_{1}}\right) t_{1}\right\}>0
\end{aligned}
$$

or

$$
\text { if } \begin{aligned}
& {\left[2\left(K+n K_{1}\right) \beta+2\left(1-e^{-\beta t_{1}}\right) \pi_{4}\right]>} \\
& >\left[\pi_{3} \beta^{2} P_{1} t_{1}^{2}+\pi_{4}\left(2+\beta t_{1}\right)\right]\left(\beta e^{-\beta h_{1}}\right) t_{1}
\end{aligned}
$$

Let

$$
\gamma\left(t_{1}\right)=\frac{2\left(K+n K_{1}\right) \beta+2\left(1-e^{-\beta t_{1}}\right) \pi_{4}}{\left[\pi_{3} \beta^{2} P_{1} t_{1}^{2}+\pi_{4}\left(2+\beta t_{1}\right)\right]\left(\beta e^{-\beta \beta_{1}}\right)}
$$

Equation (25) becomes as follows:

$$
\begin{aligned}
& \text { if } \quad 0<t_{1}<\gamma\left(t_{1}\right) \\
& \text { then } \frac{d^{2} E\left[T C U\left(t_{1}\right)\right]}{d t_{1}^{2}}>0
\end{aligned}
$$

Once we proved $E\left[T C U\left(t_{1}\right)\right]$ is convex, then setting first-derivative of $E\left[T C U\left(t_{1}\right)\right]=0$, we can find the optimal fabrication runtime $t_{1}^{*}$. Let the following be the upper and lower bounds for fabrication runtime $t_{1}^{*}$ :

$$
\begin{aligned}
& t_{1 U}^{*}=\sqrt{\frac{\left(K+n K_{1}\right) \beta+\pi_{4}}{P_{1} \beta \pi_{2}}} \\
& t_{1 L}^{*}=\text { the positive root of } \\
& \left\{\frac{-\pi_{4} \pm \sqrt{\pi_{4}^{2}+4 P_{1}\left(\pi_{2}+\pi_{3} \beta\right)\left(K+n K_{1}\right)}}{2 P_{1}\left[\pi_{2}+\pi_{3} \beta\right]}\right\}
\end{aligned}
$$

Theorem 3.1: $t_{1} L^{*}<t_{1}{ }^{*}<t_{1} U^{*}$

Setting the following first-derivative of $E\left[T C U\left(t_{1}\right)\right]=0$ :

$$
\begin{aligned}
& \frac{d E\left[T C U\left(t_{1}\right)\right]}{d t_{1}}= \\
& =\lambda\left\{\begin{array}{l}
\pi_{2}+\pi_{3}\left(\beta e^{-\beta t_{1}}\right)-\frac{\left(K+n K_{1}\right)}{t_{1}^{2} P_{1}} \\
+\left[\frac{M}{P_{1}}+\frac{h g}{\beta}\right]\left(\frac{-\left(1-e^{-\beta t_{1}}\right)}{t_{1}^{2}}+\frac{\beta e^{-\beta t_{1}}}{t_{1}}\right)
\end{array}\right\}=0
\end{aligned}
$$

That is

$$
\begin{aligned}
& \left\{\pi_{2}+\pi_{3}\left(\beta e^{-\beta t_{1}}\right)-\frac{\left(K+n K_{1}\right)}{t_{1}^{2} P_{1}}+\right. \\
& \left.+\left[\frac{M}{P_{1}}+\frac{h g}{\beta}\right]\left(\frac{-\left(1-e^{-\beta t_{1}}\right)}{t_{1}^{2}}+\frac{\beta e^{-\beta t_{1}}}{t_{1}}\right)\right\}=0
\end{aligned}
$$

Multiplying Equation (33) by $\left(P_{1} t_{1}^{2} \beta\right)$, we obtain

$$
\begin{aligned}
& \left\{\left[\pi_{2}+\pi_{3}\left(\beta e^{-\beta t_{1}}\right)\right] P_{1} t_{1}^{2} \beta-\left(K+n K_{1}\right) \beta+\right. \\
& \left.+\pi_{4}\left[-\left(1-e^{-\beta t_{1}}\right)+\beta e^{-\beta t_{1}} t_{1}\right]\right\}=0
\end{aligned}
$$

or

$$
\begin{aligned}
& {\left[\pi_{2}+\pi_{3}\left(\beta e^{-\beta t_{1}}\right)\right] P_{1} \beta t_{1}^{2}+\left(\pi_{4} \beta e^{-\beta t_{1}}\right) t_{1}-} \\
& -\left[\left(K+n K_{1}\right) \beta+\left(1-e^{-\beta t_{1}}\right) \pi_{4}\right]=0
\end{aligned}
$$

It can be seen from Equation (35) that $t_{1}{ }^{*}$ is the positive root of the following

$$
t_{1}=\frac{-\left(\beta e^{-\beta_{4}} \pi_{4}\right) \pm \sqrt{\left[\beta e^{-\beta_{4}} \pi_{4}\right]^{2}-4 P_{1} \beta\left[\pi_{2}+\pi_{3}\left(\beta e^{-\beta_{4}}\right)\right] \cdot\left[-\left[\left(K+n K_{1}\right) \beta+\left(1-e^{-\beta_{4}}\right) \pi_{4}\right]\right]}}{2\left[\pi_{2}+\pi_{3}\left(\beta e^{-\beta_{4}}\right)\right] P_{1} \beta}
$$

Further rearrange Equation (35) as follows:

$$
\begin{aligned}
& P_{1} \beta \pi_{2} t_{1}^{2}-\left[\left(K+n K_{1}\right) \beta+\pi_{4}\right]+ \\
& +\left[P_{1} \beta^{2} \pi_{3} t_{1}^{2}+\pi_{4}\left(1+\beta t_{1}\right)\right]\left(e^{-\beta t_{4}}\right)=0
\end{aligned}
$$


or

$$
\begin{aligned}
& {\left[P_{1} \beta^{2} \pi_{3} t_{1}^{2}+\pi_{4}\left(1+\beta t_{1}\right)\right]\left(e^{-\beta t_{1}}\right)=} \\
& =\left[\left(K+n K_{1}\right) \beta+\pi_{4}\right]-P_{1} \beta \pi_{2} t_{1}^{2}
\end{aligned}
$$

or

$$
e^{-\beta t_{1}}=\frac{\left[\left(K+n K_{1}\right) \beta+\pi_{4}\right]-P_{1} \beta \pi_{2} t_{1}^{2}}{P_{1} \beta^{2} \pi_{3} t_{1}^{2}+\pi_{4}\left(1+\beta t_{1}\right)}
$$

Since $e^{-\beta t_{1}}$ is the complement of cumulative density function, so $0 \leq e^{-\beta t_{1}} \leq 1$, and $e^{-\beta t_{1}}=0$ and $e^{-\beta t_{1}}=1$ are the upper and lower bounds of $e^{-\beta t_{1}}$, respectively. Now, substituting its upper and lower bounds into Equation (36), we obtain the following:

$$
\begin{aligned}
& t_{1 U}^{*}=\sqrt{\frac{\left(K+n K_{1}\right) \beta+\pi_{4}}{P_{1} \beta \pi_{2}}} \\
& t_{1 L}^{*}=\text { the positive root of } \\
& \left\{\frac{-\pi_{4} \pm \sqrt{\pi_{4}^{2}+4 P_{1}\left(\pi_{2}+\pi_{3} \beta\right)\left(K+n K_{1}\right)}}{2 P_{1}\left[\pi_{2}+\pi_{3} \beta\right]}\right\}
\end{aligned}
$$

and $t_{1} L^{*}<t_{1}^{*}<t_{1} U^{*}$.

It is noted that $t_{1}{ }^{*}$ falls within the bounds, although we cannot derive it as a closed form solution.

Let $\delta\left(t_{1}\right)=e^{-\beta t_{1}}=\frac{\left[\left(K+n K_{1}\right) \beta+\pi_{4}\right]-P_{1} \beta \pi_{2} t_{1}^{2}}{P_{1} \beta^{2} \pi_{3} t_{1}^{2}+\pi_{4}\left(1+\beta t_{1}\right)}$ (from Equation (39)),

since $0 \leq e^{-\beta t_{1}} \leq 1$, so $0 \leq \delta\left(t_{1}\right) \leq 1$. The following proposed recursive algorithm enables us to get the $t_{1}$ :

1. Initially let $\delta\left(t_{1}\right)=0$ and $\delta\left(t_{1}\right)=1$ and first compute upper and lower bounds of $\mathrm{t} 1^{*}$, respectively (that is to calculate initial values of $\left.\left[t_{1} L^{*}, t_{1} U^{*}\right]\right)$.

2. By substituting current values of $\left[\mathrm{t} 1 \mathrm{~L}^{*}, \mathrm{t} 1 \mathrm{U}^{*}\right]$ in $e^{-\beta t_{1}}$ and re-compute the new values for bounds (i.e., $\delta L$ and $\delta U)$ for $e^{-\beta t_{1}}$, where $\delta L<\delta\left(t_{1}\right)<\delta U$.

3. Let $\delta\left(t_{1}\right)=\delta L$ and $\delta\left(t_{1}\right)=\delta U$ and re-calculate and update values of bounds for $t_{1}{ }^{*}$, respectively (that is $\left.\left[t_{1} L^{*}, t_{1} U^{*}\right]\right)$.

4. Repeat steps 2 and 3, until there is no significant difference between $t_{1} L^{*}$ and $t_{1} U^{*}$ (the criterion here is no significant difference in terms of their effects on the expected system cost function $\left.E\left[T C U\left(t_{1}{ }^{*}\right)\right]\right)$.

5. Stop. Optimal fabrication runtime $t_{1}{ }^{*}$ found.

\section{Numerical example with discussion}

To ease comparison efforts for readers, the same numerical example as in Chiu [01] is used. The corresponding values of system variables are listed as follows:

$$
\begin{aligned}
& \lambda=4,000 \text { items per year, } \\
& P_{1}=10,000 \text { items per year, } \\
& P_{2}=5,000 \text { items per year, }
\end{aligned}
$$

$\beta=0.5$ per year - the mean of Poisson breakdown rate, $M=\$ 500$ per failure,

$g=0.018$ year - the fixed equipment repairing time (the same as $\left.t_{r}\right)$,

$x=[0,0.2]-$ interval of nonconforming rate which follows a uniform distribution,

$C_{R}=\$ 0.50$ - unit rework cost,

$h_{1}=\$ 0.80$ - unit holding cost per item reworked,

$K_{1}=\$ 80$ per shipment,

$n=4$ - the number of shipments per cycle,

$C_{T}=\$ 0.001$ per items shipped,

$K=\$ 450$ per cycle,

$C=\$ 2-$ unit fabrication cost,

$h=\$ 0.6$ - unit stock holding cost at the production unit, $h_{2}=\$ 1.5-$ unit stock holding cost at the sales office.

First of all, the convexity of $E\left[T C U\left(t_{1}\right)\right]$ (Equation (29)) is tested. From computations of Equations (30) and (31), $t_{1} U^{*}=0.2834$ and $t_{1} L^{*}=0.1941$ are obtained, respectively. Substitute $t_{1} U^{*}$ and $t_{1} L^{*}$ in Equations (28) and (29), we confirm both $t_{1} U^{*}<\gamma\left(t_{1} U^{*}\right)=2.1663$ and $t_{1} L^{*}<\gamma\left(t_{1} L^{*}\right)=$ 0.9233 . Therefore, $\left[\operatorname{TCU}\left(t_{1}\right)\right]$ is convex.

Then, we apply proposed recursive algorithm (as stated in end of aforementioned subsection 3.1) to find the optimal fabrication runtime $t_{1}{ }^{*}$. Table 1 exhibits the step-by-step iterative results of the algorithm. It can be seen that the initial values of $E\left[T C U\left(t_{1} U^{*}=0.2834\right)\right]=$ $\$ 11,530.67$ and $E\left[T C U\left(t_{1} L^{*}=0.1941\right)\right]=\$ 11,370.03$. By applying algorithm further, at the fourth step it shows that $E\left[T C U\left(t_{1} L^{*}\right)\right]=E\left[T C U\left(t_{1} U^{*}\right)\right]=\$ 11,366.29$, at $t_{1} U^{*}=t_{1} L^{*}$ $=0.2040$. That is the optimal replenishment runtime $t_{1}{ }^{*}=$ 0.2040 , and $E\left[T C U\left(t_{1}^{*}\right)\right]=\$ 11,366.29$.

Effects of variations in $h_{2}$ on total holding cost at sales office and on $E\left[T C U\left(t_{1}^{*}\right)\right]$ are explored and exhibited in Table 2. It is noted that as $h_{2}$ (or the ratio of $h_{2} / h$ ) increases, both total holding cost at sales office and $E\left[T C U\left(t_{1}^{*}\right)\right]$ increases notably.

Further analysis exposes effects of variations in $h_{2} / h$ ratio on $t_{1}{ }^{*}$ (see Figure 5 ). It can be seem that that as $h_{2} / h$ ratio increases, the optimal fabrication runtime $t_{1}^{*}$ declines significantly.

Moreover, analytical results reveal the effects of variations in number of shipments $\mathrm{n}$ on $E\left[T C U\left(t_{1}\right)\right]$ and on optimal runtime $t_{1}{ }^{*}$ (see Figure 6). It can be seen that is noted that as $n$ raises, $E\left[T C U\left(t_{1}\right)\right]$ goes higher slightly, but $t_{1}{ }^{*}$ goes up notably.

The effect of fabrication runtime $t_{1}$ on $E\left[T C U\left(t_{1}\right)\right]$ is explored and the result is depicted in Figure 7. It reconfirms that at $t_{1}{ }^{*}=0.2040$ the optimal $E\left[T C U\left(t_{1}\right)\right]=\$ 11,366$.

In a highly competitive business environment, our research results for such an intra-supply chain system can offer valuable in-depth information of effects of different stock holding costs of diverse sales offices on system parameters and optimal operating policy, to facilitate managerial decision making. 
Table 1: Results obtained from the proposed recursive algorithm for finding $t_{1}{ }^{*}$

\begin{tabular}{cccccccccc}
\hline$\beta$ & Step \# & $t_{1} U^{*}$ & $\begin{array}{c}\delta_{L}= \\
e^{-\beta t_{1 U}}\end{array}$ & $t_{1} L^{*}$ & $\begin{array}{c}\delta_{U}= \\
e^{-\beta t_{1 \mathrm{U}}}\end{array}$ & $\begin{array}{c}\text { Difference } \\
\text { between } \\
t_{1} U^{*} \& t_{1} L^{*}\end{array}$ & $\begin{array}{c}{[U]} \\
E\left[T C U\left(t_{1} U^{*}\right)\right]\end{array}$ & $\begin{array}{c}{[L]} \\
E\left[T C U\left(t_{1} L^{*}\right)\right]\end{array}$ & $\begin{array}{c}\text { Difference } \\
\text { between } \\
{[U] \&[L]}\end{array}$ \\
\hline 0.5 & initial & - & 0.0000 & - & 1.0000 & - & - & - & - \\
& 1st & 0.2834 & 0.8679 & 0.1941 & 0.9075 & 0.0893 & $\$ 11,530.67$ & $\$ 11,370.03$ & $\$ 160.64$ \\
& 2nd & 0.2075 & 0.9014 & 0.2036 & 0.9032 & 0.0039 & $\$ 11,366.73$ & $\$ 11,366.30$ & $\$ 0.43$ \\
& 3rd & 0.2042 & 0.9029 & 0.2040 & 0.9030 & 0.0002 & $\$ 11,366.30$ & $\$ 11,366.29$ & $\$ 0.01$ \\
& 4th & $\mathbf{0 . 2 0 4 0}$ & $\mathbf{0 . 9 0 3 0}$ & $\mathbf{0 . 2 0 4 0}$ & $\mathbf{0 . 9 0 3 0}$ & $\mathbf{0 . 0 0 0 0}$ & $\mathbf{\$ 1 1 , 3 6 6 . 2 9}$ & $\mathbf{\$ 1 1 , 3 6 6 . 2 9}$ & $\mathbf{\$ 0 . 0 0}$ \\
\hline
\end{tabular}

Table 2: Effects of variations in $h_{2}$ on total holding cost at sales office and on $E\left[T C U\left(t_{1}^{*}\right)\right]$

\begin{tabular}{|c|c|c|c|c|c|c|c|c|c|c|c|c|}
\hline$h_{2}$ & 0.30 & 0.45 & 0.60 & 0.75 & 0.90 & 1.05 & 1.20 & 1.35 & 1.50 & 1.65 & 1.80 & 1.95 \\
\hline$h_{f} / h$ ratio & 0.50 & 0.75 & 1.00 & 1.25 & 1.50 & 1.75 & 2.00 & 2.25 & 2.50 & 2.75 & 3.00 & 3.25 \\
\hline $\begin{array}{c}\text { Total holding } \\
\text { cost at sales } \\
\text { office }\end{array}$ & $\$ 264$ & $\$ 374$ & $\$ 473$ & $\$ 564$ & $\$ 649$ & $\$ 727$ & $\$ 801$ & $\$ 871$ & $\$ 937$ & $\$ 1001$ & $\$ 1061$ & $\$ 1119$ \\
\hline$E\left[T C U\left(t_{1}^{*}\right)\right]$ & $\$ 10489$ & $\$ 10617$ & $\$ 10739$ & $\$ 10854$ & $\$ 10965$ & $\$ 11071$ & $\$ 11173$ & $\$ 11271$ & $\$ 11366$ & $\$ 11459$ & $\$ 11548$ & $\$ 11636$ \\
\hline
\end{tabular}

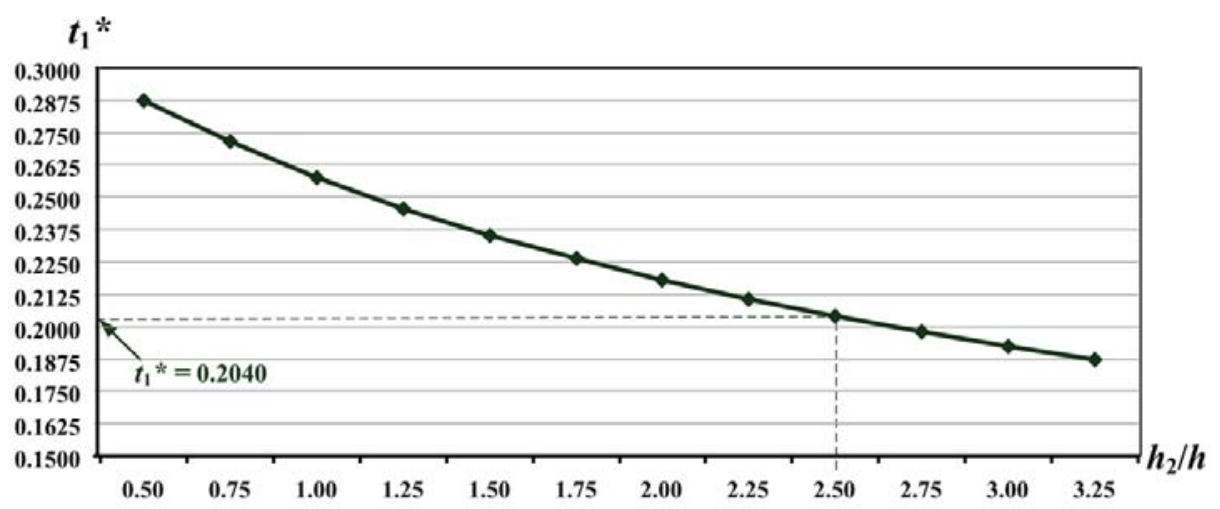

Figure 5: Effects of variations in $h_{2} / h$ ratio on $t_{1}{ }^{*}$

\section{$\mathbf{E}\left[\operatorname{TCU}\left(t_{1}\right)\right]$}

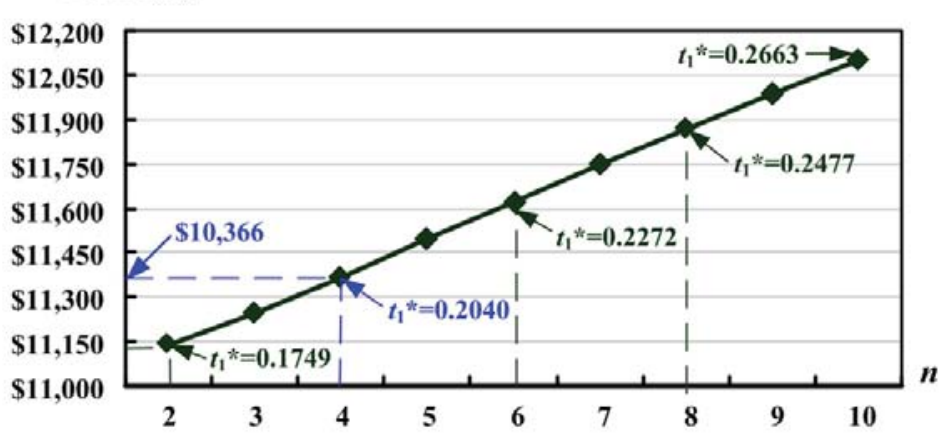

Figure 6: Effects of variations in number of deliveries $n$ on $E\left[T C U\left(t_{1}\right)\right]$ and $t_{1}^{*}$

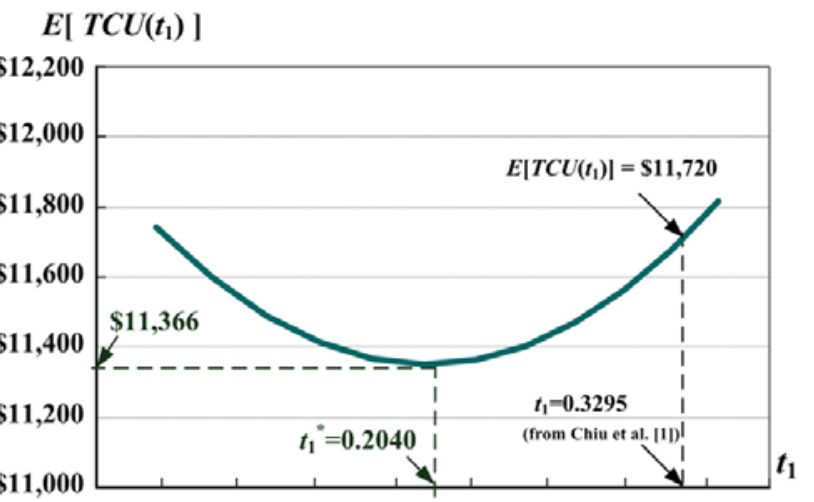

$\begin{array}{llllllll}0.064 & 0.104 & 0.144 & 0.184 & 0.224 & 0.264 & 0.304 & 0.344\end{array}$

Figure 7: Behavior of $E\left[T C U\left(t_{1}\right)\right]$ with respect to the fabrication runtime $t_{1}$ 


\section{CONCLUSION}

This study explores the optimal fabrication runtime for an imperfect intra-supply chain system. With the help of mathematical modeling and optimization techniques, we are able to obtain system cost function, theorem on convexity, and bounds for fabrication runtime. By applying a recursive algorithm, we find the optimal fabrication runtime. A numerical example helps us show how the proposed solution procedure works. Without the in-depth exploration of such a realistic intra-supply chain system, the optimal fabrication runtime and various important facts of the system cannot be revealed (see Figures 5-7 and Table 2). This study fills the research gap in this specific area, and to investigate impact from a stochastic production rate on the same model may be an interesting subject for future research.

\section{ACKNOWLEDGEMENTS}

Authors deeply thank the Ministry of Science and Technology of Taiwan for sponsor of this study (under grant no. MOST102-2410-H-324-005).

\section{APPENDIX - A}

\section{Notations}

$t_{1}=$ fabrication uptime,

$t_{2}^{\prime}=$ rework time (in the breakdown case),

$t_{\mathrm{r}}=\mathrm{a}$ constant (or maximal allowable) equipment repair time, it is the same as $g$,

$t_{3}{ }^{\prime}=$ delivery time (in the breakdown case),

$\mathrm{t}=$ time to equipment failure,

$\beta=$ number of machine failure per year - a random variable obeys the Poisson distribution,

$K=$ fabrication setup cost,

$M=$ machine repair cost,

$h=$ holding cost per product in production department,

$C_{R}=$ unit rework cost,

$h_{1}=$ unit holding cost per item reworked,

$h_{2}=$ unit holding cost at the sales office,

$K=$ fixed cost per delivery,

$C_{T}=$ unit shipping cost,

$H^{\prime}=$ on-hand inventory level at the time when rework finishes (in the breakdown case),

$\mathrm{H}_{2}$ '=on-hand inventory level at the time when machine failure happens,

$H_{1}^{\prime}=$ on-hand inventory level at the time when fabrication process finishes (in the breakdown case),

$T^{\prime}=$ cycle length (in the breakdown case),

$Q=$ batch size,

$h_{3}=$ holding cost per safety stock,

$T C_{1}\left(t_{1}\right)=$ total system cost per cycle (in the breakdown case),
$E\left[T C_{1}\left(t_{1}\right)\right]=$ expected system cost per cycle (in the breakdown case),

$t_{2}=$ rework time (in the case of no equipment failure taking place),

$t_{3}=$ delivery time (in the case of no equipment failure taking place),

$T=$ cycle length (in the case of no equipment failure taking place),

$H=$ on-hand inventory level at the time when rework finishes (in the case of no equipment failure taking place), $H_{1}=$ on-hand inventory level at the time when fabrication process finishes (in the case of no equipment failure taking place),

$T C_{2}\left(t_{1}\right)=$ total system cost per cycle (in the case of no equipment failure taking place),

$E\left[T C_{2}\left(t_{1}\right)\right]=$ expected system cost per cycle (in the case of no equipment failure taking place),

$D=$ quantity of end products (a fixed number) transported to retail store per shipment,

$I=$ number of left over products per time interval $t n$, after satisfying demand in $t n$,

$I(t)=$ on-hand inventory level at time $t$,

$I_{d}(t)=$ on-hand inventory level of defective items at time $t$,

$I_{c}(t)=$ on-hand stock level at sales office at time $t$,

$T=$ cycle length (whether an equipment failure occurs or not),

$\operatorname{TCU}\left(t_{1}\right)=$ total system cost per unit time (whether an equipment failure occurs or not),

$E\left[T C U\left(t_{1}\right)\right]=$ the long-run average system cost per unit time (whether an equipment failure occurs or not). 


\section{REFERENCES}

1. Chiu, S.W. (2007) Production run time problem with machine breakdowns under AR control policy and rework, Journal of Scientific \& Industrial Research, 66, pp. 979-988.

2. Taft, E.W. (1918) The most economical production lot, Iron Age, 101, pp. 1410-1412.

3. Silver, E.A., Pyke, D.F., Peterson, R. (1998) Inventory Management and Production Planning and Scheduling, John Wiley \& Sons, Inc., New York.

4. Nahmias, S. (2009) Production \& Operations Analysis, McGraw-Hill Inc., New York.

5. Goyal, S.K. (1977) Integrated inventory model for a single supplier-single customer problem. International Journal of Production Research, 15, pp. 107-111.

6. Schwarz, L.B., Deuermeyer, B.L., Badinelli, R.D. (1985) Fill-rate optimization in a one-warehouse $\mathrm{N}$-identical retailer distribution system, Management Science, 31, pp.488-498.

7. Banerjee, A., Banerjee, S. (1994) A coordinated order-up-to inventory control policy for a single supplier and multiple buyers using electronic data interchange. International Journal of Production Economics, 35, pp. 85-91.

8. Tyan, J., Wee, H.M. (2003) Vendor managed inventory: A survey of the Taiwanese grocery industry, Journal of Purchasing \& Supply Managament, 9, pp. 11-18.

9. Sarker, R.A., Khan, L.R. (1999) Optimal batch size for a production system operating under periodic delivery policy, Computers \& Industrial Engineering, 37, pp. 711-730.

10. Diponegoro, A., Sarker, B.R. (2006) Finite horizon planning for a production system with permitted shortage and fixed-interval deliveries, Computers \& Operations Research, 33, pp. 2387-2404.

11. Cheng, C-B. (2011) Reverse auction with buyer-supplier negotiation using bi-level distributed programming, European Journal of Operational Research, 211, pp. 601-611.

12. Giri, B.C., Maiti, T. (2012) Supply chain model for a deteriorating product with time-varying demand and production rate, Journal of the Operational Research Society, 63, pp. 665-673.

13. Balaji, M., Velmurugan, V., Prapa, M., Mythily, V. (2016) A fuzzy approach for modeling and design of agile supply chains using interpretive structural modeling, Jordan Journal of Mechanical and Industrial Engineering, 10(1), pp. 67-74.

14. Chiu, Y-S.P., Chiang, K-W., Chiu, S.W., Song, M-S. (2016) Simultaneous determination of production and shipment decisions for a multi-product inventory system with a rework process, Advances in Production Engineering \& Management, 11(2), pp. 141-151.
15. Fergany, H.A. (2016) Probabilistic multi-item inventory model with varying mixture shortage cost under restrictions, SpringerPlus, 5(1), Art. No. 1351, pp.113.

16. Qu, S., Ji, Y. (2016) The worst-case weighted multi-objective game with an application to supply chain competitions, PLoS One, 11(1), Art. No. e0147341, pp. 1-22.

17. Mičieta, B., Herčko, J., Botka, M., Zrnić, N. (2016) Concept of intelligent logistic for automotive industry, Journal of Applied Engineering Science, 14(2), pp. 233-238.

18. Henig, H., Gerchak, Y. (1990) Structure of periodic review policies in the presence of random yield, Operations Research, 38, pp. 634-643.

19. Groenevelt, H., Pintelon, L., Seidmann, A. (1992) Production lot sizing with machine breakdowns, Management Science, 38, pp. 104-123.

20. Boone, T., Ganeshan, R., Guo, Y., Ord, J.K. (2000) The impact of imperfect processes on production run times, Decision Sciences, 31, pp. 773-785.

21. Lin, G.C., Gong, D-C. (2006) On a production-inventory system of deteriorating items subject to random machine breakdowns with a fixed repair time, Mathematical and Computer Modelling, 43, pp. 920-932.

22. Sana, S.S., Chaudhuri, K. (2010) An EMQ model in an imperfect production process, International Journal of Systems Science, 41, pp. 635-646.

23. Barlow, R.E., Proschan, F. (1965) Mathematical Theory of Reliability. Wiley, New York.

24. Shih, W., 1980. Optimal inventory policies when stock-outs result from defective products. International Journal of Production Research, 18, pp. 677686.

25. Hariga, M., Ben-Daya, M. (1998) Note: the economic manufacturing lot-sizing problem with imperfect production processes: bounds and optimal solutions, Naval Research Logistics, 45, pp. 423-433.

26. Wee, H.M., Yu, J., Chen, M.C. (2007) Optimal inventory model for items with imperfect quality and shortage back ordering, Omega, 35, pp. 7-11.

27. Widyadana, G.A., Wee, H.M. (2012) An economic production quantity model for deteriorating items with preventive maintenance policy and random machine breakdown, International Journal of Systems Science, 43(10), pp. 1870-1882.

28. Rivera-Gómez, H., Gharbi, A., Kenné, J.P. (2013) Production and quality control policies for deteriorating manufacturing system, International Journal of Production Research, 51(11), pp. 3443-3462.

29. Chiu, S.W., Kuo, J-S., Chiu, V., Chiu, Y-S.P. (2016) Cost minimization for a multi-product fabrication-distribution problem with commonality, postponement, and quality assurance. Mathematical and Computational Applications, 21(3), Art. No. 38, pp. 1-17. 
30. Dinesh, K.S., Ashwanth, A.R., Karthikeyan, S., Nithyanandam, G.K. (2016) Investigation to improve the new product development process of mono block pump using additive manufacturing, International Journal of Mechanical and Production Engineering Research and Development, 6(2), pp. 77-88.

31. Romero-Jabalquinto, A., Velasco-Téllez, A., Zambrano-Robledo, P., Bermúdez-Reyes, B. (2016) Feasibility of manufacturing combustion chambers for aeronautical use in Mexico, Journal of Applied Research and Technology, 14(3), pp. 167-172.

32. Sinaga, S., Pertiwi, L.S., Ardian, T., Zuhri. (2016) Inventory simulation optimization under non stationary demand, International Journal of Applied Engineering Research, 11(1), pp. 524- 529.

33. Zhang, D., Zhang, Y., Yu, M. (2016) A machining process oriented modeling approach for reliability optimization of failure-prone manufacturing systems, Journal of Engineering Research, 4(3), pp. 128-143.

34. Dhaiban, A.K., Baten, M.A., Aziz, N. (2017) A manufacturing-inventory control model with defective and deteriorating items, Far East Journal of Mathematical Sciences, 101(8), pp. 1691-1709.
35. Chiu, S.W., Liu, C-J., Li, Y-Y., Chou, C-L. (2017) Manufacturing lot size and product distribution problem with rework, outsourcing, and discontinuous inventory distribution policy, International Journal for Engineering Modelling, 30(1-4), pp. 49-61.

36. Khanna, A., Kishore, A., Jaggi, C.K. (2017) Strategic production modeling for defective items with imperfect inspection process, rework, and sales return under two-level trade credit, International Journal of Industrial Engineering Computations, 8(1), pp. 85-118.

37. Ajbar, A., Ali, E. (2017) Study of advanced control of ethanol production through continuous fermentation, Journal of King Saud University - Engineering Sciences, 29(1), pp. 1-11.

38. Oblak, L., Kuzman, M.K., Grošelj, P. (2017) A fuzzy logic-based model for analysis and evaluation of services in a Manufacturing company, Journal of Applied Engineering Science, 15(3), pp. 258-271.

39. Buckova, M., Krajcovic, M., Jerman, B. (2017) Impact of digital factory tools on designing of warehouses, Journal of Applied Engineering Scien 